OPEN ACCESS

Edited by:

Kangle $L v$,

South-Central University for

Nationalities, China

Reviewed by:

Li Yuhan,

Chongqing Technology and Business

University, China

Zhenyi Zhang,

Dalian Nationalities University, China

*Correspondence:

Xuan Xu

xuxuan@cqu.edu.cn

Fangying $\mathrm{J}$

jfy@cqu.edu.cn

Yan Qiu

93441147@qq.com

†These authors have contributed equally to this work

Specialty section: This article was submitted to Catalysis and Photocatalysis,

a section of the journal

Frontiers in Chemistry

Received: 02 September 2020

Accepted: 28 October 2020

Published: 10 December 2020

Citation:

Gu X, Luo Y, Li Q, Wang R, Fu S, Lv X, He Q, Zhang Y, Yan Q, Xu X, Ji F and Qiu $Y$ (2020) First-Principle Insight Into the Effects of Oxygen Vacancies on the Electronic, Photocatalytic, and

Optical Properties of Monoclinic $\mathrm{BiVO}_{4}(001)$. Front. Chem. 8:601983. doi: 10.3389/fchem.2020.601983

\section{First-Principle Insight Into the Effects of Oxygen Vacancies on the Electronic, Photocatalytic, and Optical Properties of Monoclinic $\mathrm{BiVO}_{4}(001)$}

\author{
Xiaosong $\mathrm{Gu}^{1+}$, Yujie $\mathrm{Luo}^{1+}$, Qi $\mathrm{Li}^{1+}$, Rui Wang ${ }^{2}$, Shiqi Fu' ${ }^{1}$, Xiulong $\mathrm{Lv}^{1}$, Qian He ${ }^{1}$, \\ Ying Zhang ${ }^{1}$, Qiutong Yan ${ }^{1}$, Xuan $\mathrm{Xu}^{1 *}$, Fangying $\mathrm{Ji}^{1 *}$ and Yan Qiu ${ }^{3 *}$ \\ ${ }^{1}$ Key Laboratory of Three Gorges Reservoir Region's Eco-Environment, Ministry of Education, Chongqing University, \\ Chongqing, China, ${ }^{2}$ Department of Physics, Center for Quantum Materials and Devices, Institute for Structure and Function, \\ Chongqing University, Chongqing, China, ${ }^{3}$ School of Architectural Engineering, Yunnan Agricultural University, Kunming, \\ China
}

In this paper, first-principle calculations were performed to investigate the effects of oxygen $(\mathrm{O})$ vacancies (Ovac) on the crystal structure, electronic distribution, adsorption energies of $\mathrm{O}_{2}$ and $\mathrm{H}_{2} \mathrm{O}$ and the density of states (DOS) of monoclinic bismuth vanadate $\left(\mathrm{m}-\mathrm{BiVO}_{4}\right)$. Ovac were stable when incorporated into $\mathrm{m}-\mathrm{BiVO}_{4}(001)$ and increased the adsorption energy of $\mathrm{O}_{2}$. Ovac changed the $\mathrm{V} 3 \mathrm{~d}$ orbitals of $\mathrm{m}-\mathrm{BiVO}_{4}(001)$ by adding a new band gap level, causing the redundant electrons of $\mathrm{V}$ atoms to become carriers and promoting the separation efficiency of electrons and holes. To verify the first-principle calculations, $\mathrm{m}_{-} \mathrm{BiVO}_{4}$ with different Ovac levels was prepared via hydrothermal synthesis. X-ray diffraction (XRD) patterns confirmed the existence of the (001) crystal surface of $\mathrm{m}_{-} \mathrm{BiVO}_{4}$. In addition, X-ray photoelectron spectroscopy (XPS) and electron spin resonance (ESR) spectroscopy of $\mathrm{m}-\mathrm{BiVO}_{4}$ confirmed the presence of Ovac and demonstrated that, as the Ovac level increased, the number of superoxide radicals $\left(\mathrm{O}_{2}^{-} \cdot\right)$ and hydroxyl radicals $(\cdot \mathrm{OH})$ produced increased. In addition, m-BiVO with a higher Ovac level possessed superior photocatalytic properties to and degraded rhodamine $\mathrm{B}(\mathrm{RhB})$ dye nearly 2-fold faster than $\mathrm{m}_{-} \mathrm{BiVO}_{4}$ with a lower Ovac level. Finally, the removal rate of RhB increased from 23 to $44 \%$. All experimental results were in good agreement with the first-principle calculated results.

\section{Keywords: photocatalytic, $\mathrm{BiVO}_{4}$, oxygen vacancy, first-principles method, pollutant degradation}

\section{HIGHLIGHTS}

- A first-principles calculation simulation was used to construct the (001) crystal plane of $\mathrm{BiVO}_{4}$ containing oxygen vacancies (Ovac), and the effects of Ovac on the crystal were determined.

- Monoclinic bismuth vanadate $\left(\mathrm{m}-\mathrm{BiVO}_{4}\right)$ with different Ovac was prepared, and its photocatalytic performance was studied.

- Ovac content affects the V3d orbital of $\mathrm{BiVO}_{4}(001)$, adds a new band gap energy level and improves the separation efficiency of electrons and holes.

- This study verified the first-principles calculation simulation results, confirming the mechanism by which Ovac enhance catalytic performance. 


\section{INTRODUCTION}

Recently, environmental issues have increasingly become the focus of attention, and sustainable development has become a global consensus. Utilization of solar energy is a key solution for solving environmental issues. Thus, the development of photocatalytic semiconductors for organic pollutant degradation and hydrogen production (Liu et al., 2019; Lu et al., 2020) has become a hot research topic (Alsalka et al., 2018). Since the discovery of photoinduced decomposition of water $\left(\mathrm{H}_{2} \mathrm{O}\right)$ by $\mathrm{TiO}_{2}$ electrodes (Fujishima and Honda, 1972), many studies have focused on improving the photocatalytic degradation of pollutants in $\mathrm{H}_{2} \mathrm{O}$.

At present, photocatalysts still have multiple problems with their use, including their low utilization of solar energy, high photogenerated electron-hole recombination rate and poor light stability (Zhang et al., 2019). To address these problems and improve the performance of photocatalytic materials, the further exploration of the catalytic mechanism of photocatalytic materials and a deeper understanding of the basic physical and chemical properties of these materials are necessary.

Density functional theory (DFT) is one of the most popular and common theories used in condensed matter physics, computational physics, and computational chemistry. DFT has been widely used in the theoretical study of catalyst performance parameters, including in the study of crystal defects and the adsorption energy differences that exist between different crystal surfaces (Wang J. et al., 2018; Wang Y. et al., 2018; Zhang et al., 2018). Thus, DFT is thus highly suitable for studying the basic properties of photocatalytic materials. For example, Yang et al. (2007) studied the effect of nitrogen $(\mathrm{N})$ concentration on the formation energy and electronic band structure of $\mathrm{N}$-doped $\mathrm{TiO}_{2}$ using DFT calculations. The study showed that, at low doping levels, N-doped anatase formed a localized N-2p state above the valence band, resulting in a decrease in photon transition energy and confirming a red shift was caused by the N-doping of $\mathrm{TiO}_{2}$. Similarly, the results obtained by Liu et al. (2011) confirmed the red shift produced by zinc oxide absorption was caused by carbon- (C-) doping using DFT calculations.

Bismuth vanadate $\left(\mathrm{BiVO}_{4}\right)$ is a relatively new photocatalyst. In 1998, Kudo et al. (1998) reported the first application of $\mathrm{BiVO}_{4}$ in the field of photocatalysis. This study showed that, under visible light irradiation, $\mathrm{BiVO}_{4}$ photocatalytically decomposed hydrogen peroxide to produce oxygen $(\mathrm{O})$ when silver ions were used as the electron capture agent. Recently, the use of $\mathrm{BiVO}_{4}$ as a photocatalytic material has received an increasing amount of attention. Its primary crystal structures include tetragonal and monoclinic phases, and the photocatalytic effect of the monoclinic phase is stronger than that of the tetragonal phase (Kudo et al., 1999; Tokunaga et al., 2001). As a photocatalytic material with a visible light response, the negative aspects of the low band gap energy of $\mathrm{BiVO}_{4}$ include the following properties: its electrons and holes are easily recombined, its migration ability is low, and its photocatalytic efficiency is low (Rao et al., 2014). To solve these problems, previous research performed by our group mixed $\mathrm{BiVO}_{4}$ with various $\mathrm{C}$ materials with high electronic conductivities, including $\mathrm{C}$ nanotubes and nanosheets (Zhao et al., 2016, 2017). Crystal defects, such as O vacancies (Ovac), can increase the charge carrier density in crystals, promoting the separation of the bulk charge and surface charge, and accelerate the charge transfer at the interface (Zhang et al., 2011; Li et al., 2015).

Although several studies have explored the effects of Ovac on the crystal structure, adsorption energy and band structure of monoclinic $\mathrm{BiVO}_{4}\left(\mathrm{~m}-\mathrm{BiVO}_{4}\right)$ (Yuan et al., 2017; Ullah et al., 2018; Wang et al., 2020), studies that include both theoretical calculations and photocatalytic experiments are rare. In addition, in those studies, the effects of adsorption energy and electron distribution of Ovac on photocatalytic materials were studied using theoretical calculations. The mechanism developed using theoretical calculations was verified experimentally by studying the degradation of pollutants using photocatalytic materials. Therefore, the physical origin of Ovac in photocatalytic materials remains to be explored.

This study focused on using DFT calculations to determine the effects of Ovac on $\mathrm{m}-\mathrm{BiVO}_{4}$ with simulations and subsequent verification via experimentation. Because of limited computing resources and ease of use, the (001) crystal plane actually present in the crystal structure of $\mathrm{m}-\mathrm{BiVO}_{4}$ was selected for this study. First, the (001) crystal surface of $\mathrm{BiVO}_{4}$ containing Ovac was constructed. The simulation and calculation of its basic properties, including its density of states (DOS), electron distribution and adsorption energy, showed Ovac change the energy band structure of $\mathrm{BiVO}_{4}$. The position of the Ovac is affected by electrons donated by the $\mathrm{V}$ atom, and the resulting new energy band enhanced the photocatalytic effect of $\mathrm{BiVO}_{4}$. To verify the simulation results, $\mathrm{BiVO}_{4}$ with different levels of Ovac was prepared, and the optical and catalytic properties of these different types of $\mathrm{BiVO}_{4}$ were characterized. The results showed Ovac increase the catalytic performance of $\mathrm{BiVO}_{4}$ without significantly changing the crystal structure of the material. In addition, Ovac significantly enhanced the separation of electrons and holes and increased the generation of free radicals during the photoreaction itself.

\section{COMPUTATIONAL METHODOLOGY AND RESULTS}

\section{Computational Methodology}

The crystal structure of $\mathrm{m}-\mathrm{BiVO}_{4}$ corresponds to a $\mathrm{I} 2 / \mathrm{b}$ space group structure with the following lattice parameters: $\mathrm{a}=5.1956$ $\AA, \mathrm{b}=5.0935 \AA, \mathrm{c}=11.7044 \AA$, and $\gamma=90.383^{\circ}$ (Figure 1A) (Sleight et al., 1979). The $\mathrm{m}-\mathrm{BiVO}_{4}(001)$ plane structure was obtained from the optimized $\mathrm{m}-\mathrm{BiVO}_{4}$ bulk unit cell using a vacuum region of $20 \AA$. A $9.69 \times 10.75 \times 22.15-\AA^{3}$ supercell was constructed with six layers, and the bottom two layers were constrained (Figures 1B,C). The plane with Ovac was obtained based on the optimized $\mathrm{m}-\mathrm{BiVO}_{4}(001)$ plane by deleting an $\mathrm{O}$ atom (Figure 1D).

The original $\mathrm{O}_{2}-\mathrm{BiVO}_{4}$ (Figures 2A,C) and $\mathrm{H}_{2} \mathrm{O}-\mathrm{BiVO}_{4}$ hybrid systems (Figures 2E,G) were obtained by adding $\mathrm{O}_{2}$ or $\mathrm{H}_{2} \mathrm{O}$ into the optimized $\mathrm{m}-\mathrm{BiVO}_{4}(001)$ plane both with and without Ovac. 


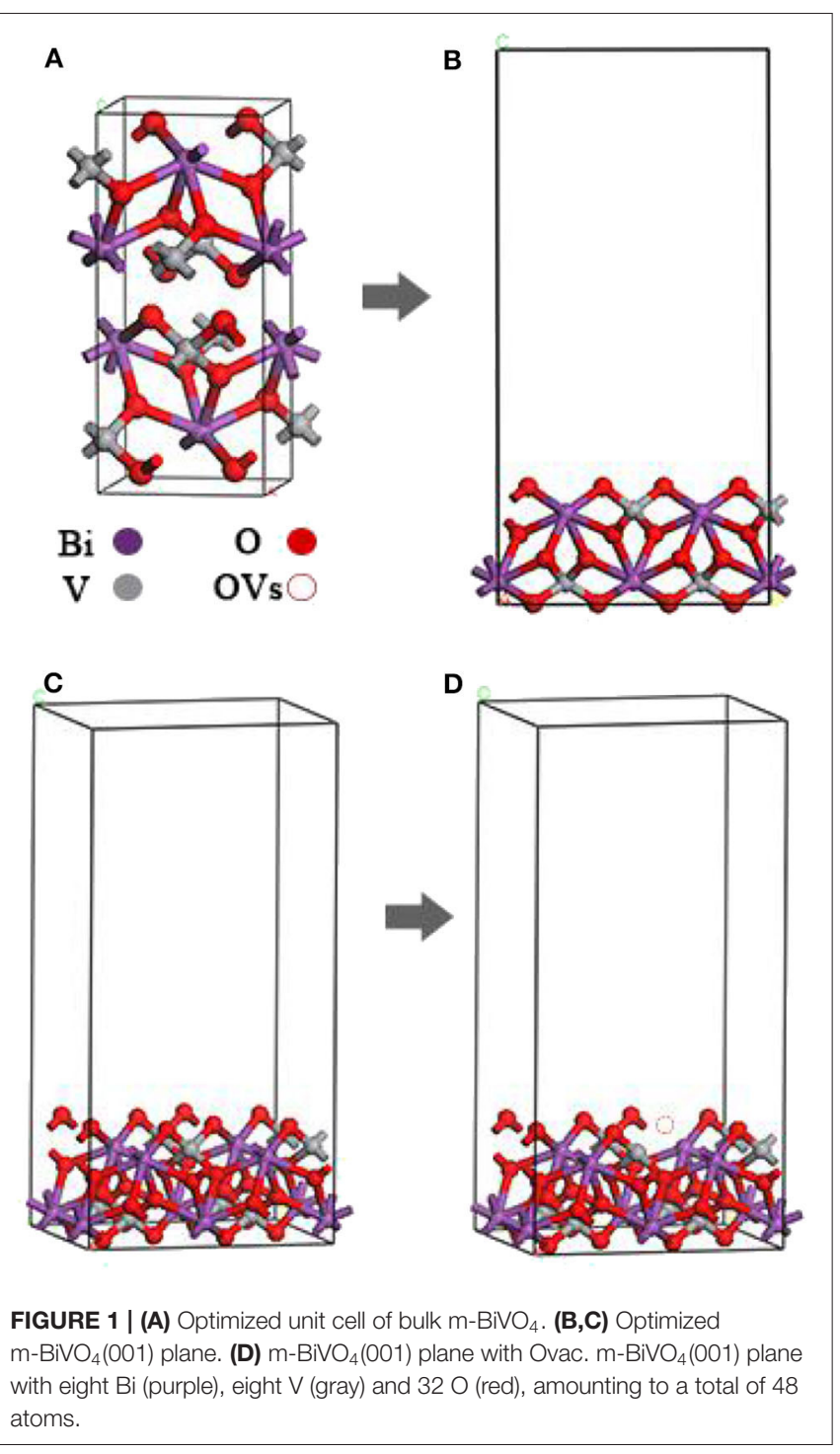

In this work, all computations were performed within the framework of DFT as implemented in the Vienna ab initio simulation package (VASP) (Kresse and Furthmüller, 1996). The general gradient approximation (GGA) in the Perdew-BurkeErnzerhof (PBE) form (Perdew et al., 1996) was used to express the exchange-correlation energy of the interacting electrons with the frozen-core full-potential projector augmented wave (PAW) method (Blochl, 1994). A plane-waves basis set with a cutoff energy of $450 \mathrm{eV}$ and a conjugate gradient algorithm were applied to determine the electronic ground state using energy and force convergence thresholds of $1 \times 10^{-5} \mathrm{eV}$ and $0.01 \mathrm{eV} \AA^{-1}$, respectively. Monkhorst-Pack grids were used to perform the integrations over the Brillouin zone (Monkhorst and Pack, 1976). For the bulk m-BiVO 4 unit cell, $10 \times 10 \times 6 \mathrm{k}$-point meshes were used; for the primitive cell of an $\mathrm{O}$ molecule, $1 \times 1 \times 1 \mathrm{k}$ point meshes were used; and for the $\mathrm{m}-\mathrm{BiVO}_{4}(001)$ plane and the supercells of the interface, $4 \times 4 \times 1 \mathrm{k}$-point meshes were used. Because DFT-GGA commonly underestimates the band gap of
$\mathrm{BiVO}_{4}($ Kresse and Furthmüller, 1996), a more accurate screened Coulomb hybrid functional, HSE06, with 16\% Hartree-Fock (HF) exchange (Wadnerkar and English, 2013; Zhou and Dong, 2017) was used to compute band structure and DOS. To reduce the HSE06 computational time, the band structure and DOS of the bulk $\mathrm{m}-\mathrm{BiVO}_{4}$ were calculated using a k-point mesh of $5 \times 5 \times 3$ for the exact-exchange HF kernel.

Traditional density functionals are unable to provide an accurate description of van der Waals (vdW) interactions because of the dynamical correlations between fluctuating charge distributions. In interface models, vdW interactions are expected to be dominant; thus, the DFT-D2 method of Grimme (2006) was adopted for this work. The total energy $\left(\mathrm{E}_{\text {total }}\right)$ is represented by the following equation:

$$
\mathrm{E}_{\mathrm{total}}=\mathrm{E}_{\mathrm{KS}-\mathrm{DFT}}+\mathrm{E}_{\mathrm{vdW}}
$$

where $\mathrm{E}_{\mathrm{KS}-\mathrm{DFT}}$ represents the conventional Kohn-Sham DFT energy and $\mathrm{E}_{\mathrm{vdW}}$ represents the dispersion correction (Blochl, 1994).

\section{Computational Results Crystal Structure}

After optimizing the structures of the $\mathrm{m}-\mathrm{BiVO}_{4}$ cell, perfect $\mathrm{BiVO}_{4}(001)$ crystal plane and $\mathrm{BiVO}_{4}(001)$ crystal plane with Ovac, the lattice parameters of the three systems were compared (Table 1). Ovac produced little effect on the crystal structure of $\mathrm{BiVO}_{4}$, and the lattice parameters did not change significantly.

\section{Adsorption Energies of $\mathrm{O}_{2}$ and $\mathrm{H}_{2} \mathrm{O}$}

As shown in Figures 2A-D, the $\mathrm{O}_{2}$ molecules were incorporated into the perfect $\mathrm{BiVO}_{4}(001)$ crystal plane and $\mathrm{BiVO}_{4}(001)$ crystal plane with Ovac, respectively. These figures show the $\mathrm{O}_{2}$ molecule moved upward and away from the interface. At the interface of the crystal plane containing Ovac, the $\mathrm{O}_{2}$ molecule shifted downward and subsequently occupied the position of the original Ovac after structural optimization.

The Figures 2E,G show the $\mathrm{H}_{2} \mathrm{O}$ molecules were incorporated into the perfect $\mathrm{BiVO}_{4}(001)$ crystal plane and $\mathrm{BiVO}_{4}(001)$ crystal plane with Ovac, respectively. The initial distances of the $\mathrm{O}$ atom and the two $\mathrm{H}$ atoms between the Ovac (or the $\mathrm{O}$ atom) in $\mathrm{H}_{2} \mathrm{O}$ molecules were $1.392,2.22$, and $1.76 \AA$. After structural optimization, the distances of the $\mathrm{O}$ atom and the two $\mathrm{H}$ atoms between the Ovac (or the $\mathrm{O}$ atom) in $\mathrm{H}_{2} \mathrm{O}$ molecules were 2.568, 2.516, and $2.155 \AA$ (Figures 2F,H). These figures show the $\mathrm{H}_{2} \mathrm{O}$ molecules migrated upward and away from the interface.

At the interface of the crystal plane containing Ovac, the $\mathrm{H}_{2} \mathrm{O}$ molecules did not migrate a significant distance after structural optimization.

The adsorption energies of these systems were calculated using the following equation (Xu et al., 2013):

$$
E_{a}=E_{O}\left(E_{H}\right)+E_{B}-E_{O-B}\left(E_{H-B}\right)
$$

where $E_{a}$ represents the adsorption energy; $E_{O}$ and $E_{H}$ represent the total energies of the $\mathrm{O}$ and $\mathrm{H}_{2} \mathrm{O}$ molecules, respectively; $E_{O-B}$ and $E_{H-B}$ represent the total energies of the interface system of the $\mathrm{O}$ and $\mathrm{H}_{2} \mathrm{O}$ molecules, respectively; and $E_{B}$ represents the 


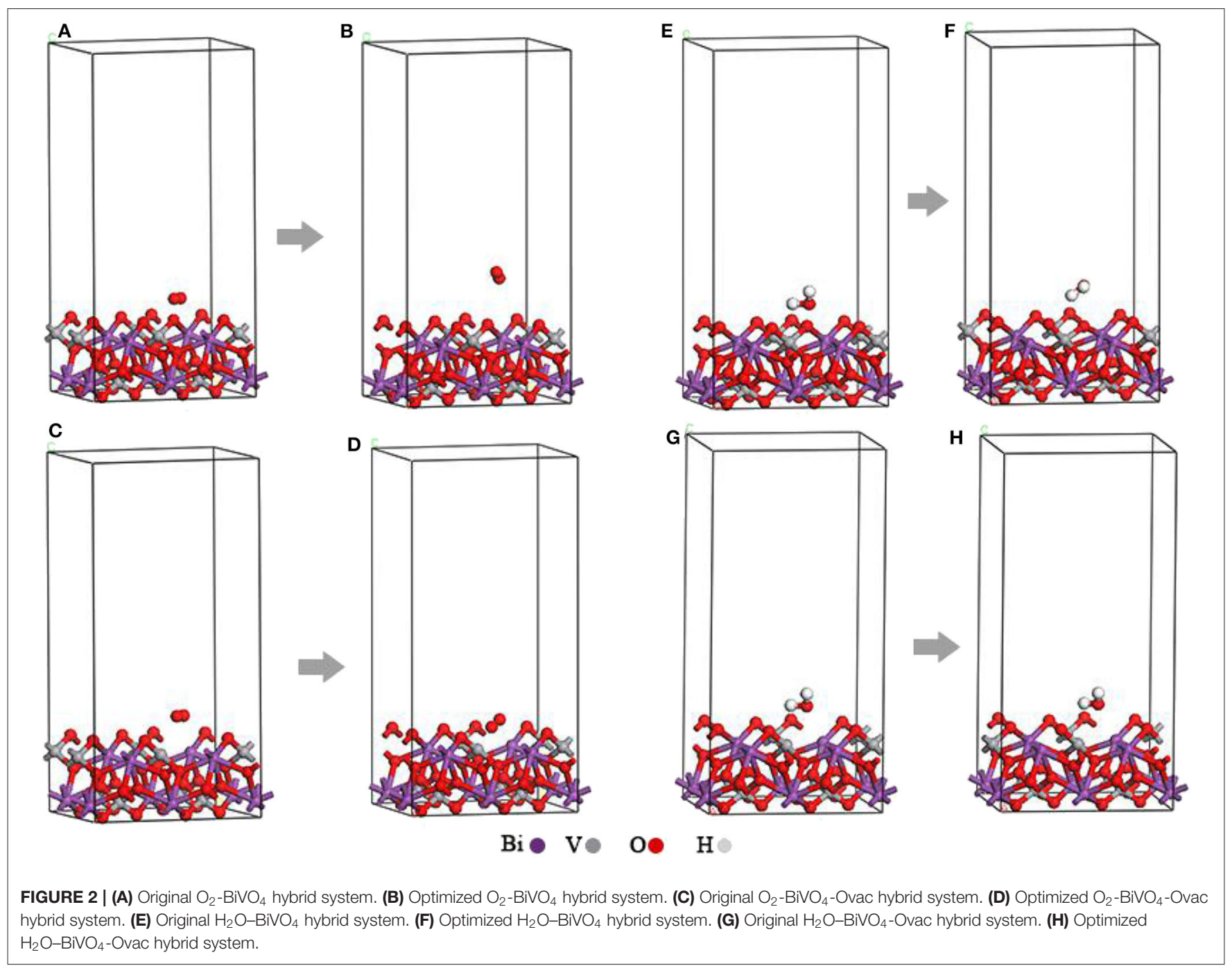

TABLE 1 | Calculated lattice constants of $\mathrm{BiVO}_{4}$ with and without Ovac.

\begin{tabular}{|c|c|c|c|c|c|c|c|}
\hline & $a(\AA)$ & $b(\AA)$ & $c(\AA)$ & $\alpha^{\circ}$ & $\beta^{\circ}$ & $\gamma^{\circ}$ & $\mathbf{V}\left(\AA^{3}\right)$ \\
\hline Bulk m-BivO 4 & 5.227 & 5.131 & 11.777 & 90.000 & 90.000 & 90.107 & 315.859 \\
\hline $\mathrm{m}-\mathrm{BiVO}_{4}(001)$ & 9.843 & 10.701 & 21.779 & 89.829 & 89.943 & 88.772 & 2293.595 \\
\hline $\begin{array}{l}\text { m-BivO } \\
\text { Ovac }\end{array}$ & 9.690 & 10.755 & 22.148 & 90.002 & 89.999 & 90.961 & 2308.848 \\
\hline
\end{tabular}

total energy of the $\mathrm{BiVO}_{4}$ system. When calculating the perfect crystal plane and the plane with Ovac, corresponding values need to be substituted. The corresponding calculation results are presented in Table 2.

The adsorption energy calculation results (Table 2) showed the adsorption energy of $\mathrm{O}$ molecules at the Ovac interfaces increased significantly from 0.045 to $2.862 \mathrm{eV}$ while the adsorption energy of $\mathrm{H}_{2} \mathrm{O}$ molecules decreased slightly by $0.192 \mathrm{eV}$, demonstrating Ovac produced little effect on the adsorption energy of $\mathrm{H}_{2} \mathrm{O}$ molecules. However, Ovac increased the adsorption energy between the system and $\mathrm{O}$ molecules by
TABLE 2 | Adsorption energy calculation results.

\begin{tabular}{lcc}
\hline & $\begin{array}{c}\text { Adsorption energy } \\
\text { of } \mathbf{O}_{\mathbf{2}}\end{array}$ & $\begin{array}{c}\text { Adsorption energy } \\
\text { of } \mathbf{H}_{\mathbf{2}} \mathbf{O}\end{array}$ \\
\hline${\mathrm{m}-\mathrm{BiVO}_{4}(001) \text { plane }}$ & $0.045 \mathrm{eV}$ & $0.464 \mathrm{eV}$ \\
${\mathrm{m}-\mathrm{BiVO}_{4}(001) \text { plane with Ovac }}$ & $2.862 \mathrm{eV}$ & $0.272 \mathrm{eV}$
\end{tabular}

$2.817 \mathrm{eV}$, which was far beyond the range of vdW adsorption energies ( $\mathrm{Xu}$ et al., 2013). Therefore, the adsorption of the $\mathrm{O}$ molecule at the Ovac was most likely due to chemical adsorption, and the $\mathrm{O}$ molecule most likely interacted with the $\mathrm{Bi}$ and $\mathrm{V}$ atoms in the Ovac. For the $\mathrm{O}$ molecule adsorbed to the Ovac, the length of the O-O bond changed from 1.236 to $1.368 \AA$ and the activity of the $\mathrm{O}$ molecules increased.

\section{DOS and Electron Localization Function (ELF)}

As shown in Figure 3, the band gap of the $\mathrm{BiVO}_{4}$ cell was $\sim 2.5 \mathrm{eV}$, which is near the actual value of $2.3-2.5 \mathrm{eV}$ (Kudo 


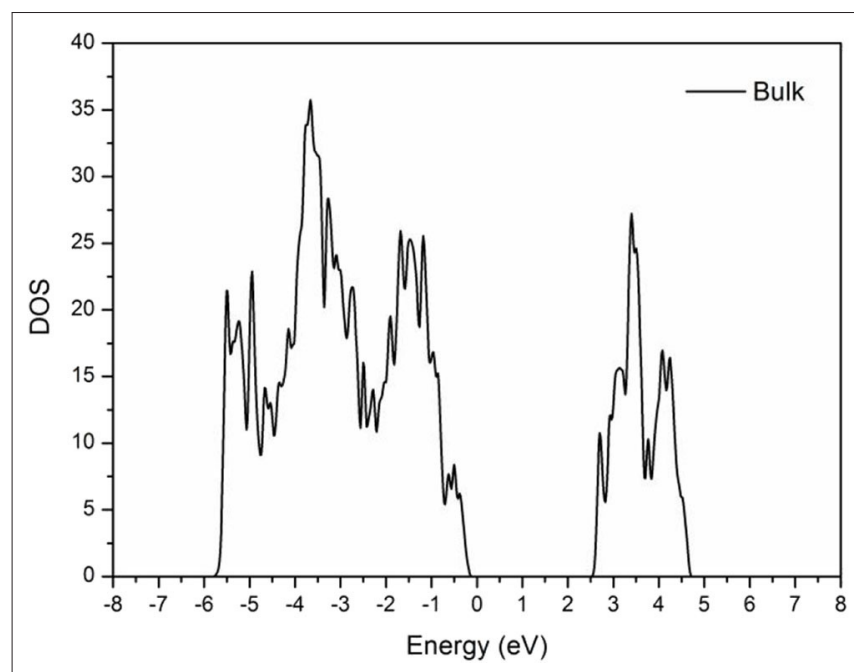

FIGURE 3 | DOS of $\mathrm{m}-\mathrm{BiVO}_{4}$.

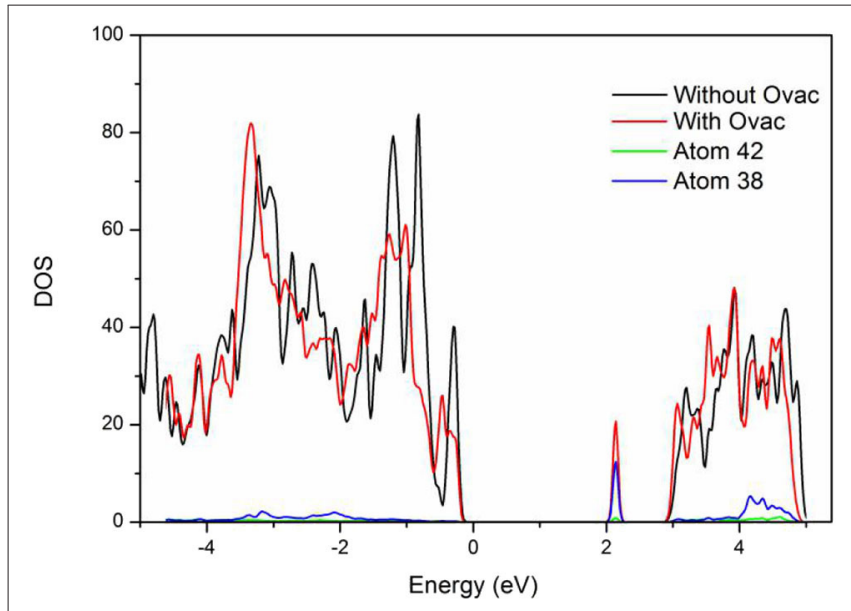

FIGURE 4 | DOS of the perfect $\mathrm{BiVO}_{4}(001)$ plane and the $\mathrm{BiVO}_{4}(001)$ plane with Ovac.

et al., 1998; Sayama et al., 2006; Yuan et al., 2017). This result demonstrated the calculated parameters were correct.

As shown in Figure 4, the band gap width of the perfect $\mathrm{BiVO}_{4}(001)$ crystal plane was $2.75 \mathrm{eV}$, which was higher than that of a single cell. Most likely, this result was caused by interfacial effects. However, new energy levels were formed in the system with Ovac. Analysis of the new energy levels was performed to further elucidate their composition: the results showed these levels were formed by atoms 38 and $42, \mathrm{~V}$ and Bi located near the Ovac. These two atoms were the same atoms that bonded with the $\mathrm{O}$ atoms that originally existed in these locations. The newly generated energy levels were primarily composed of the corresponding V3d orbitals; thus, most likely, O molecules were primarily chemically adsorbed by $\mathrm{V}$ atoms.

In addition, the results showed that when the newly generated energy levels produced by Ovac were not considered, the band gap width of the crystal plane containing Ovac was $2.75 \mathrm{eV}$. The band gap width of the perfect $\mathrm{BiVO}_{4}(001)$ crystal plane and the crystal plane containing Ovac did not change significantly, indicating Ovac could not change the overall band gap width at a certain content and could only increase catalyst performance via the newly generated energy levels. The new energy levels acted as trapping centers for electrons and significantly increased the electron migration efficiency, a result consistent with how Ovac function as positive charge centers.

A more detailed analysis of the electronic distribution of the system was conducted to achieve a more thorough understanding of its chemical adsorption. The results of this analysis are presented in Figure 5.

Electron localization function (ELF) is a tool used for analyzing charge transfer between atoms. Becke and Edgecombe (1990) proposed a method for calculating local electron distribution using graphs. This method first analyzes electrons near the nuclear area, combination bonding area and lone pair electrons of a system. Second, this method determines the characteristics and types of chemical bonds (Burdett and McCormick, 1998). ELF produces values in the range of $0-1$. An ELF value of 1 is indicative of a high localization of electrons, i.e., a high probability of electron localization (marked with red in Figure 5). An ELF value of $1 / 2$ is indicative of the uniform distribution of electrons in this location. An ELF value of 0 is indicative of the complete delocalization of electrons, i.e., no electrons are present in this location (marked with blue in Figure 5). Figure 5e shows the electron distribution of Ovac, although the electron cloud shape was different from that when $\mathrm{O}$ atoms were present (Figure 5a). Furthermore, as shown in Figures 5g,h, the ELF was near 1 when the Ovac was closer to the $\mathrm{V}$ atom, demonstrating that as the distance between the elections and $\mathrm{V}$ atom decreases, the localization of the elections increases. The results indicated the electrons in this region were primarily supplied by the $\mathrm{V}$ atom. When $\mathrm{O}$ atoms were present, $\mathrm{V}$ atoms provided electrons to bond with the $\mathrm{O}$ atoms. When $\mathrm{O}$ atoms were not present, the redundant electrons from $\mathrm{V}$ atoms became carriers in photocatalytic reactions.

\section{PREPARATION AND CHARACTERIZATION OF SAMPLES}

\section{Syntheses of Materials}

Bismuth nitrate pentahydrate $\left(\mathrm{Bi}\left(\mathrm{NO}_{3}\right)_{3} \cdot 5 \mathrm{H}_{2} \mathrm{O}\right)$, glycerol $\left(\mathrm{C}_{3} \mathrm{H}_{8} \mathrm{O}_{3}\right)$, sodium metavanadate dihydrate $\left(\mathrm{NaVO}_{3} \cdot 2 \mathrm{H}_{2} \mathrm{O}\right)$ and alcohol $\left(\mathrm{C}_{2} \mathrm{H}_{6} \mathrm{O}\right)$ were provided by Chengdu Kelong Chemical Reagent Factory (Chengdu, Sichuan, China). All reagents were analytical grade and were not purified further. Deionized $\mathrm{H}_{2} \mathrm{O}$ was used in all applicable experiments.

The O-containing photocatalyst was mixed with a specific reducing agent, either at room temperature or heated, to extract $\mathrm{O}$ from the crystal lattice to form Ovac. This study used reducing glycerin for sample preparation of samples with Ovac.

$\mathrm{m}-\mathrm{BiVO}_{4}$ Ovac were prepared using a hydrothermal method in which $0.4 \mathrm{mmol}$ of $\mathrm{Bi}\left(\mathrm{NO}_{3}\right)_{3} \cdot 5 \mathrm{H}_{2} \mathrm{O}$ powder was dissolved in 


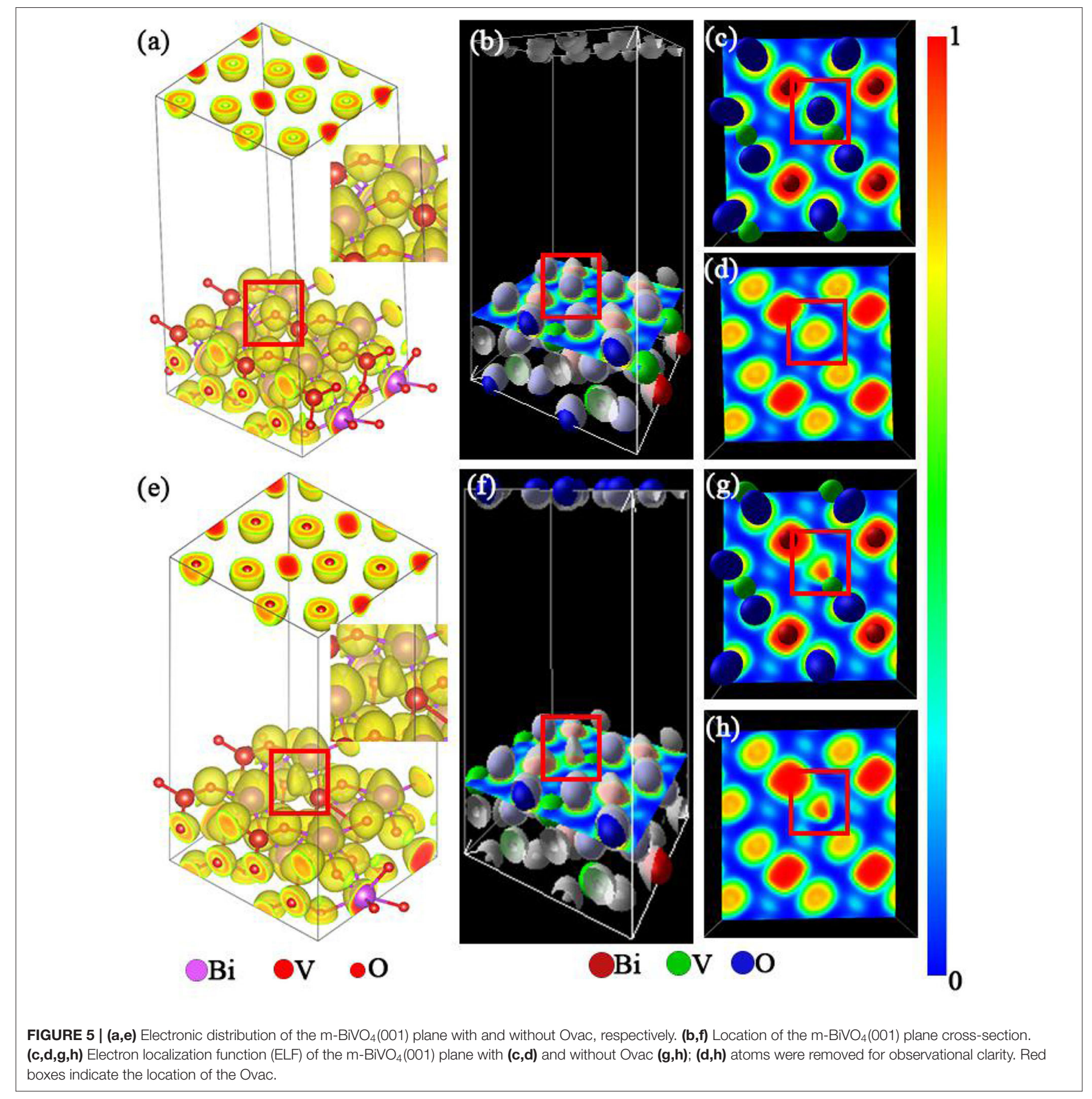

$16 \mathrm{~mL}$ of glycerol under vigorous stirring. The resulting solution was stirred for $1 \mathrm{~h}$. In addition, $0.4 \mathrm{mmol}$ of $\mathrm{NaVO}_{3} \cdot 2 \mathrm{H}_{2} \mathrm{O}$ was dissolved in $16 \mathrm{~mL}$ of deionized $\mathrm{H}_{2} \mathrm{O}$ under vigorous stirring. The solution was stirred for $0.5 \mathrm{~h}$ at room temperature, at which point the solution became homogeneous and transparent. Subsequently, the $\mathrm{NaVO}_{3} \cdot 2 \mathrm{H}_{2} \mathrm{O}$ solution was added dropwise to the $\mathrm{Bi}\left(\mathrm{NO}_{3}\right)_{3} \cdot 5 \mathrm{H}_{2} \mathrm{O}$ solution under vigorous stirring over the course of $0.5 \mathrm{~h}$, forming a yellowish suspension. The resulting suspension was heated for $8 \mathrm{~h}$ at $180^{\circ} \mathrm{C}$ in a 50 $\mathrm{mL}$ polytetrafluoroethylene-lined stainless steel autoclave. After cooling to room temperature, the precipitate was collected via centrifugation, thoroughly washed with distilled $\mathrm{H}_{2} \mathrm{O}$ and absolute ethanol and dried for $4 \mathrm{~h}$ at $60^{\circ} \mathrm{C}$ in air to yield $\mathrm{m}$ $\mathrm{BiVO}_{4}$-Ovac. Ovac were expected to disappear during the redox reaction; thus, the obtained $\mathrm{m}-\mathrm{BiVO}_{4}$-Ovac powder was then calcined at $300^{\circ} \mathrm{C}$ in a muffle furnace for 12 and $24 \mathrm{~h}$ in air, respectively. Subsequently, the powder was removed from the furnace, and the products were stored at $20^{\circ} \mathrm{C}$ in a hermetic bag. The resulting products are hereafter referred to as $\mathrm{m}-\mathrm{BiVO}_{4}$ Ovac- $12 \mathrm{~h}$ and $\mathrm{m}-\mathrm{BiVO}_{4}$-Ovac-24h. 


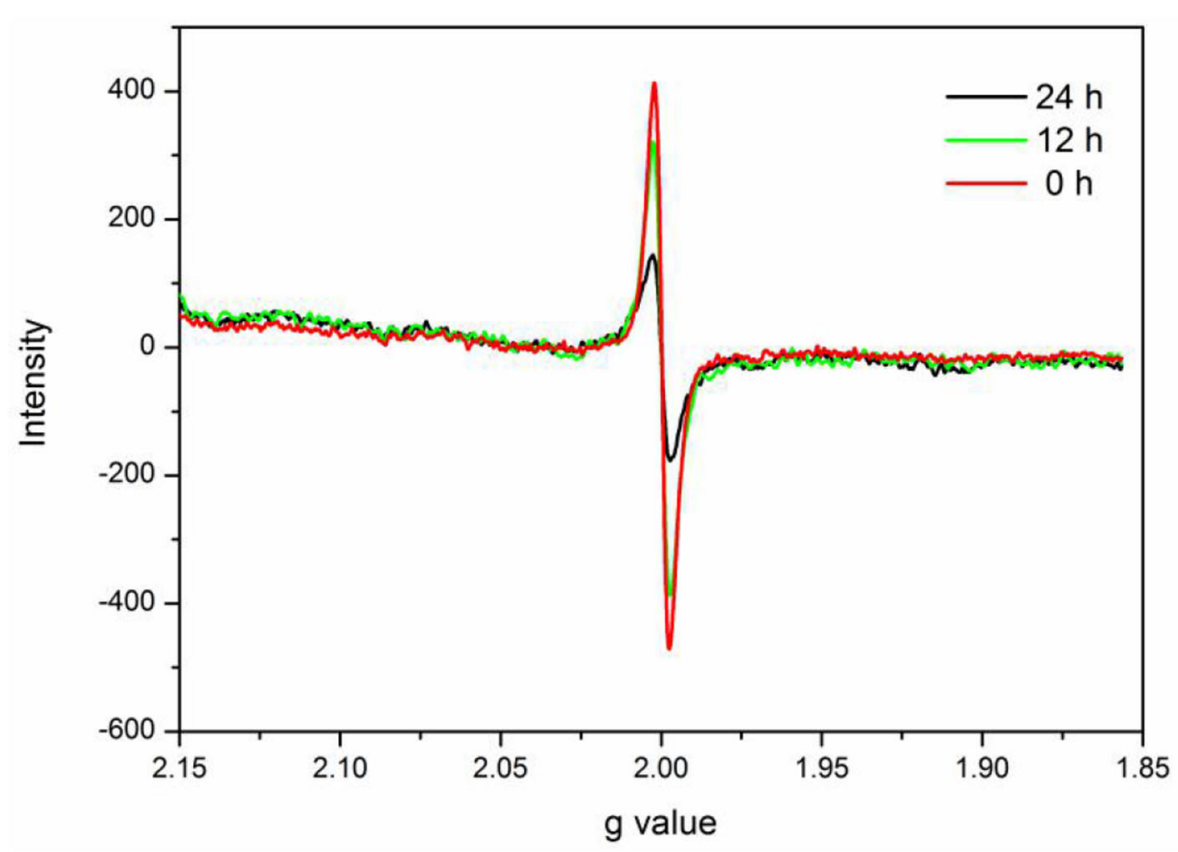

FIGURE 6 | ESR spectra of m-BiVO 4 -Ovac, BivO 4 -Ovac-12h, and $\mathrm{BiVO}_{4}-\mathrm{Ovac}-24 \mathrm{~h}$.
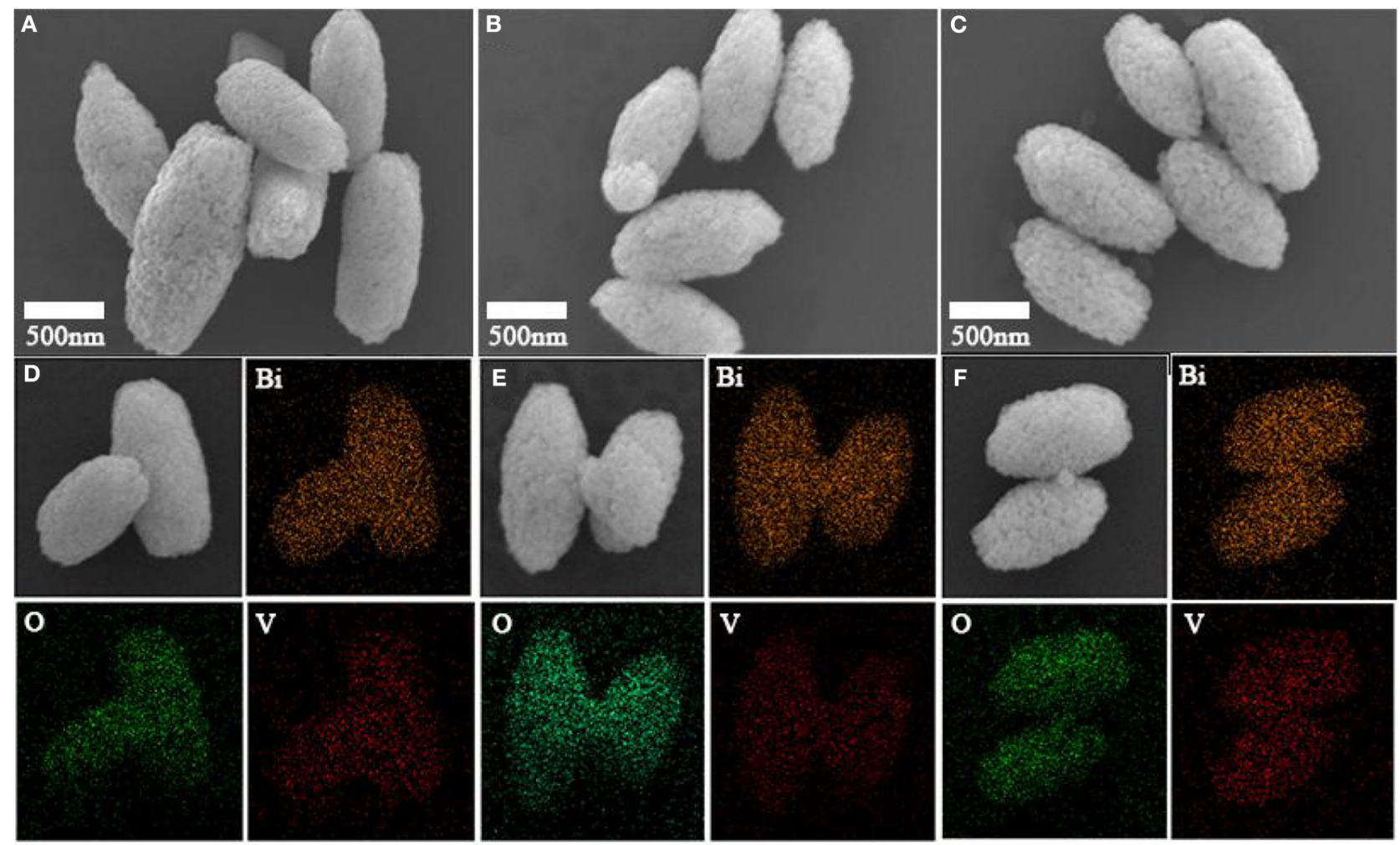

FIGURE 7 | SEM images of (A) BiVO 4 -Ovac, (B) BiVO 4 -Ovac-12h, and (C) BiVO 4 -Ovac-24h. EDS of (D) BiVO 4 -Ovac, (E) BiVO 4 -Ovac-12h, and (F) $\mathrm{BiVO}_{4}$-Ovac-24h. The morphologies of $\mathrm{BiVO}_{4}-\mathrm{Ovac}, \mathrm{BiVO}_{4}-\mathrm{Ovac}-12 \mathrm{~h}$, and $\mathrm{BiVO}_{4}$-Ovac-24h were olive-shaped and exhibited uniform size distributions. 


\section{Photocatalytic Activity}

The light source used for the photocatalytic reactions was a 500W Xe lamp (YM-GHX-VI, Shanghai Yuming Co., Ltd., China). The photocatalytic activities of the samples were determined by measuring the degradation rate of rhodamine $\mathrm{B}(\mathrm{RhB})$ dye under simulated solar irradiation. First, $20 \mathrm{mg}$ of sample was dispersed in $50 \mathrm{~mL}$ of $\mathrm{RhB}$ solution $(10 \mathrm{mg} / \mathrm{L})$ via sonication for $10 \mathrm{~min}$. Second, the solution was stirred for $30 \mathrm{~min}$ in the dark to establish adsorption-desorption equilibrium. Third, the light source was turned on, and the solution was stirred continuously for $8 \mathrm{~h}$. A 5 -mL sample was taken every $2 \mathrm{~h}$. Fourth, the sample was centrifuged at $5000 \mathrm{r} / \mathrm{min}$, the supernatant was separated from the precipitate and used to determine the RhB concentration. $\mathrm{RhB}$ degradation was monitored by measuring the absorbance of the supernatant at a wavelength of $554 \mathrm{~nm}$ with a UVVis spectrophotometer.

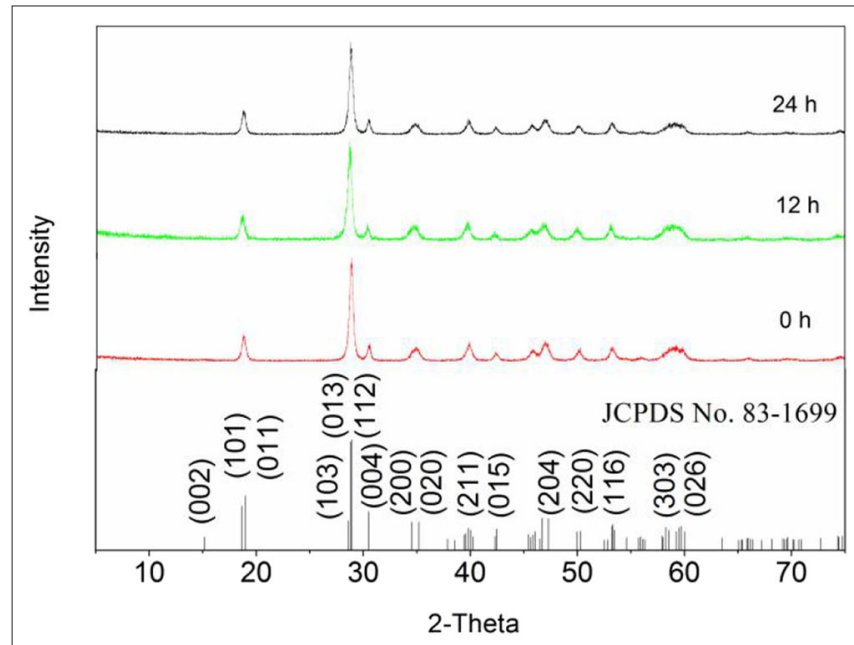

FIGURE 8 | XRD patterns of the samples.

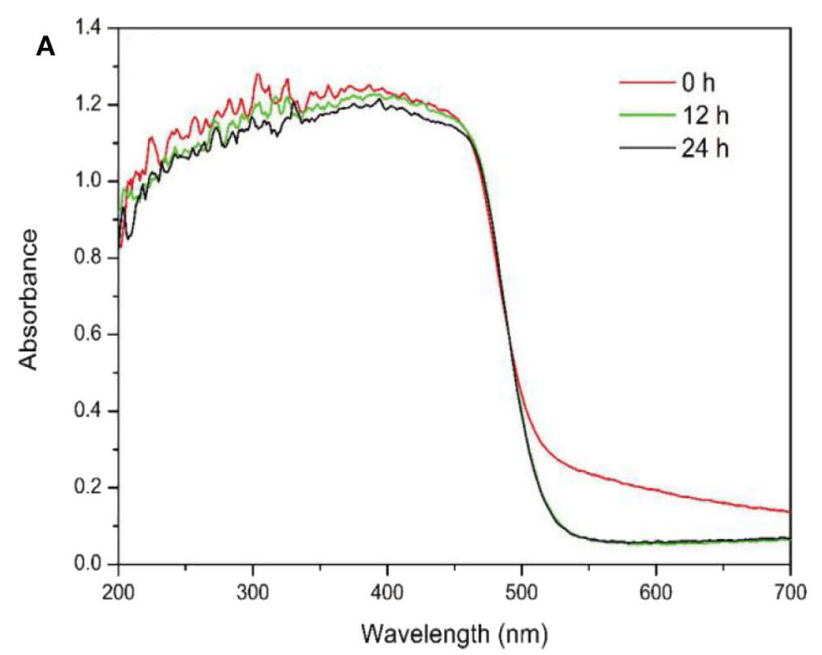

\section{Characterization}

The crystalline structures of all samples were characterized by Xray diffraction (XRD) using a Rigaku D/Max-rB diffractometer with $\mathrm{Cu} \mathrm{Ka}$ radiation. Scanning electron microscopy (SEM) images were acquired with a JOEL JSM-7800F microscope. Energy dispersive X-ray (EDX) images were acquired with an EDX100A-4. UV-Vis diffuse reflectance spectroscopy (DRS) was performed with a Hitachi U-3001 UV-Vis spectrometer. Electron spin resonance (ESR) spectroscopy was performed using a JES FA200 X-band ESR spectrometer operating in the X-band at $0.907 \mathrm{GHz}$ and $0.998 \mathrm{~mW}$.

\section{RESULTS AND DISCUSSION}

In this study, verification of the existence of Ovac in experimental samples was important. ESR spectroscopy is useful for investigating unpaired electrons in materials and was used to provide evidence for the presence of Ovac in this study.

The ESR spectrum of $\mathrm{BiVO}_{4}$-Ovac exhibits a fingerprint signal at about $\mathrm{g}=2.0$ (Figure 6) (Shi et al., 2018; Qiu et al., 2019), which proved the existence of Ovac. The signal decreased as the calcination time increased, suggesting Ovac were removed during the high-temperature annealing process.

\section{Morphology and Structure of Crystals}

The results showed the prepared $\mathrm{BiVO}_{4}$ powder possessed a grain-like microstructure that was $\sim 1$ micron in length and $500 \mathrm{~nm}$ in width. The surface of the $\mathrm{BiVO}_{4}$ powder consisted of uneven particles. The corresponding energy dispersive spectroscopy (EDS) results also showed the uniform composition of $\mathrm{Bi}, \mathrm{V}$, and $\mathrm{O}$ elements in the particles (Figures 7D-F). The morphologies and structures of the three samples, which are shown in Figure 7, showed the microstructures of the three samples were identical and did not change upon the introduction of Ovac.

The morphologies of $\mathrm{BiVO}_{4}$-Ovac, $\mathrm{BiVO}_{4}$-Ovac-12h, and $\mathrm{BiVO}_{4}-\mathrm{OV}-24 \mathrm{~h}$, shown in Figures 7A-C, respectively, were not

FIGURE 9 | (A) UV-Vis DRS spectra of the samples. (B) $(\text { Ahv })^{2}$ and hv plots of the samples.

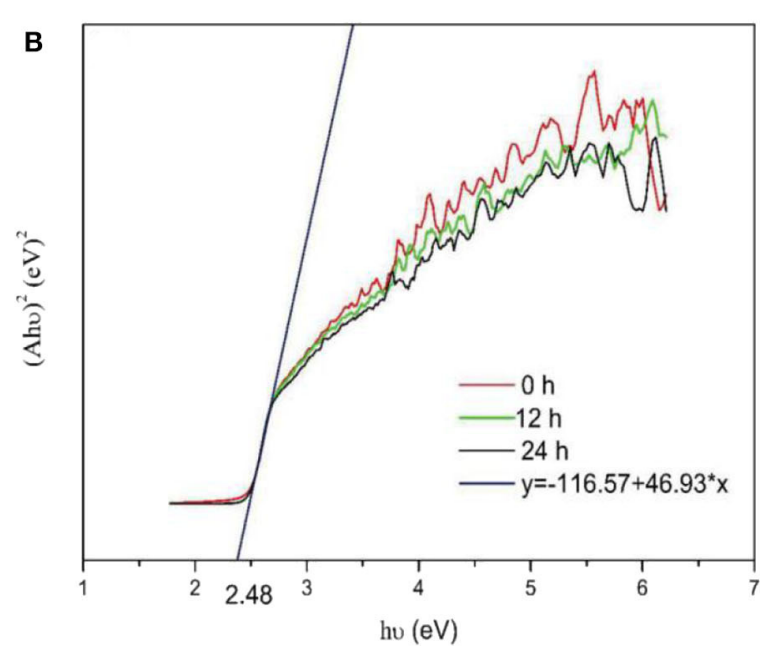



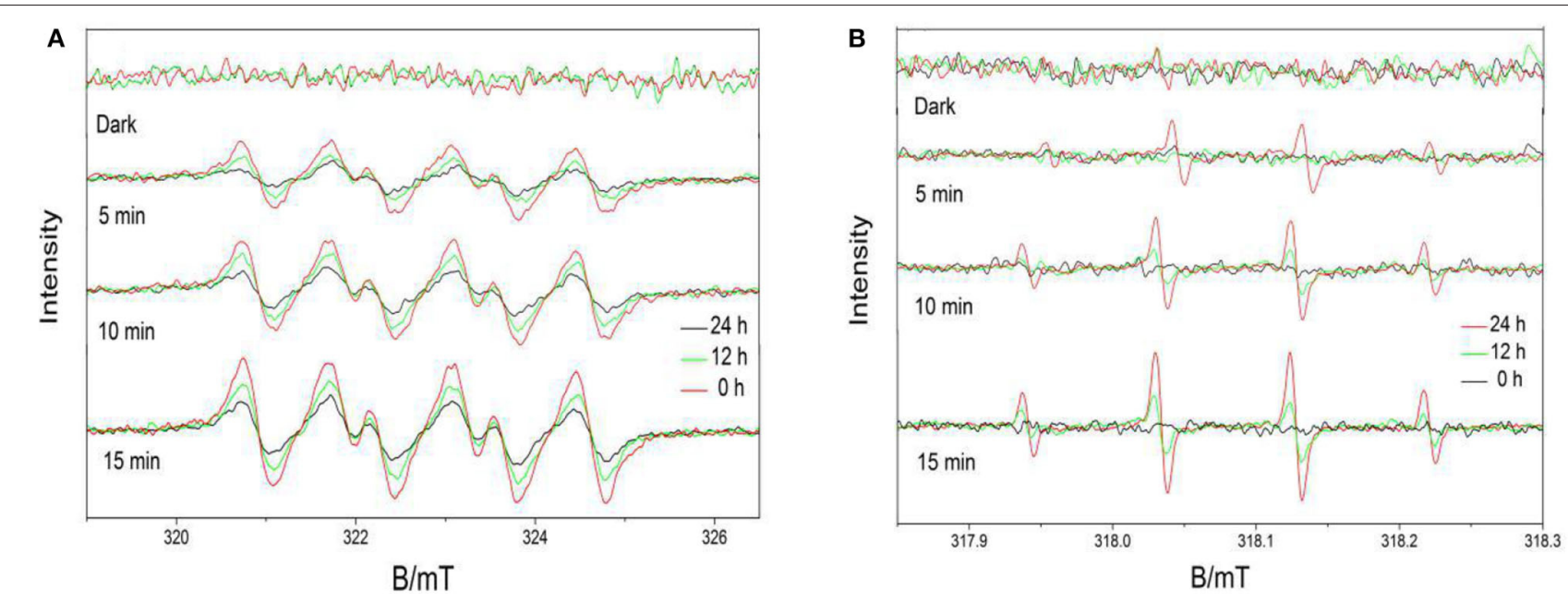

FIGURE 10 | 5,5-Dimethyl-1-pyrroline-N-oxide (DMPO) spin-trapping ESR spectra obtained under visible light for (A) DMPO-superoxide (DMPO-.O $2_{2}^{-}$) samples and (B) DMPO-hydroxyl radical (DMPO-.OH) samples.

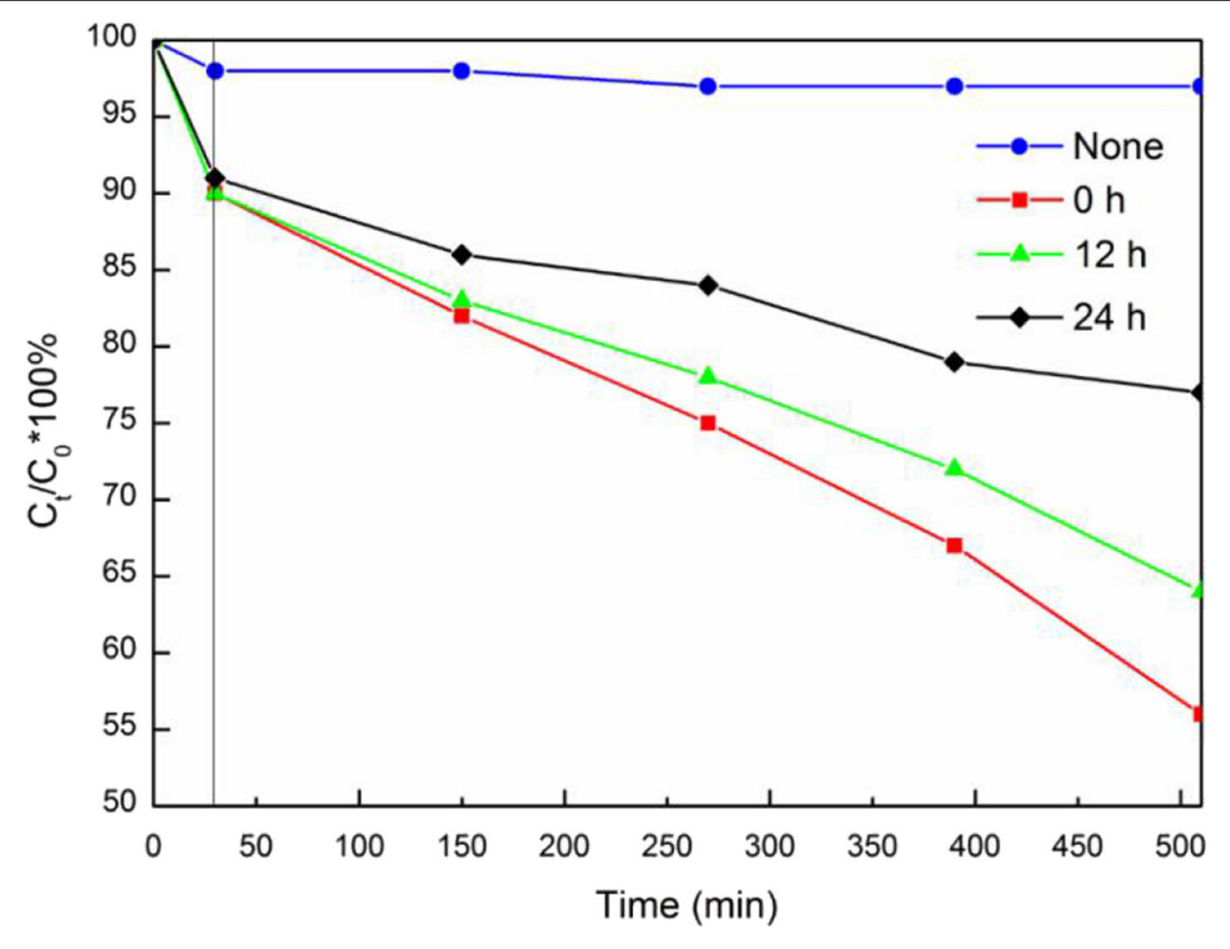

FIGURE 11 | Degradation of rhodamine B by different samples.

significantly different. These results showed calcining did not change the morphology of $\mathrm{BiVO}_{4}$. In addition, changes in the level of Ovac did not significantly affect the morphology of $\mathrm{BiVO}_{4}$.

Generally, among the low-Miller-index surfaces, the (001) crystal plane tends to be the preferred growth orientation (Han et al., 2018; Lardhi et al., 2020). Furthermore, because Xi and Ye (2010) demonstrated the monoclinic phase of $\mathrm{BiVO}_{4}$ exists in the (001) crystal plane orientation, the (001) crystal plane was selected for theoretical simulations.
The crystal structures of the samples were all consistent with that of m-BiVO4. All diffraction peaks of the phases were characterized by XRD (JCPDS No. 83-1699). Figure 8 shows the peaks of the three samples were basically the same and the diffraction at $2 \theta=30.5^{\circ}$ was indicative of that of BiVO4(001), demonstrating calcining did not change the crystal structure of BiVO4 and the (001) crystal plane of BiVO4 was present. In addition, changes in the level of Ovac did not significantly affect the crystal structure of BiVO4. 


\section{Optical Characteristics and Catalytic Performance}

UV-Vis DRS was used to investigate the optical absorption characteristics of the samples. No significant changes were observed in the UV-Vis DRS spectra of the samples before and after calcination, as shown in Figure 9A. The energy band structure of a semiconductor determines its photocatalytic activity, and the band gaps of the samples were estimated using the following equation:

$$
\mathrm{Ah} v=\mathrm{C}\left(h v-E_{g}\right)^{1 / 2}
$$

where $A, \mathrm{~h}, v$, and $E_{g}$ represent the absorption coefficient, Planck's constant, incident light frequency and band gap energy, respectively. Figure 9B shows the band gap of samples was estimated to be $2.48 \mathrm{eV}$. The results indicated the Ovac did not enhance absorption. In addition, changes in the Ovac level did not significantly affect the band gaps of the samples.

This result differed from the theoretical calculation results, which showed Ovac resulted in new energy levels. For the theoretical calculations, because of limited computing resources, a model using only 48 atoms and one Ovac was built. The solubility of Ovac in the model was very high. However, the surface Ovac concentration in the actual prepared samples were not as high as that in the theoretical calculations. In addition, the Ovac concentration did not vary significantly between samples; thus, the theoretical results should be different from the experimental results. If the computing resources had been sufficient, a larger number of atoms could have been used to construct a more accurate model. According to the theoretical model, using an Ovac concentration similar to that used in the experimental studies could have provided better results.

To further understand the effects of Ovac on the photocatalytic properties of the samples, the ability of the samples to produce free radicals was investigated.

Based on the ESR results, which are shown in Figures 10A,B, signals with intensities corresponding to the characteristic peaks of DMPO-superoxide (DMPO-. $\mathrm{O}_{2}^{-}$) and DMPO-hydroxyl radical (DMPO--OH) adducts were observed when the reactions were performed under visible light irradiation but not when the reactions were performed in the dark. The peak intensities further increased as the irradiation time increased. Furthermore, the peak intensities decreased as the calcination time increased. The results indicated the Ovac enhanced the ability of the samples to produce free radicals. The photocatalytic properties of the samples obtained herein were consistent with the ESR results.

The photocatalytic performance of $\mathrm{BiVO}_{4}$ at different Ovac levels was determined by comparing their $\mathrm{RhB}$ degradation efficiencies. As shown in Figure 11, increasing the Ovac level increased the $\mathrm{RhB}$ degradation rate of the sample under

\section{REFERENCES}

Alsalka, Y., Granone, L., Ramadan, W., Hakki, A., Dillert, R., and Bahnemann, D. (2018). Iron-based photocatalytic and photoelectrocatalytic nano-structures: facts, perspectives, and expectations. Appl. Catal. B Environ. 244, 1065-1095. doi: 10.1016/j.apcatb.2018.12.014 simulated solar irradiation. The $\mathrm{RhB}$ degradation percentages in the presence of $\mathrm{BiVO}_{4}-\mathrm{OV}, \mathrm{BiVO}_{4}-\mathrm{OV}-12 \mathrm{~h}$ and $\mathrm{BiVO}_{4}{ }^{-}$ OV-24h after $480 \mathrm{~min}$ of solar irradiation were 23, 36, and $44 \%$, respectively (Figure 11). Thus, the presence of Ovac in $\mathrm{BiVO}_{4}$ enhanced the photocatalytic properties of the samples.

\section{CONCLUSION}

The computational, SEM, XRD, and ESR results of this study demonstrated Ovac exhibited little effect on the crystal structure of $\mathrm{BiVO}_{4}$ and the lattice parameters did not change significantly. Changes in the Ovac level did not significantly change the morphology of $\mathrm{BiVO}_{4}$. Both the DOS and ELF results verified Ovac affected V3d orbitals, added a new band gap level, caused the redundant electrons from $\mathrm{V}$ atoms to become carriers, increased the adsorption energy of the $\mathrm{O}$ molecule and promoted the separation efficiency of electrons and holes. Although UVVis DRS showed the samples exhibited no change in band structure, the free radical detection results and photocatalytic reaction simulation experiments confirmed that Ovac improved the photocatalytic properties of materials. The results of this study showed the new energy level formed by the $\mathrm{V}$ atom did not significantly change the overall optical absorption of the material at a certain Ovac level; however, because the $\mathrm{V}$ atom had an electron capture center, the new energy level caused by a higher level of Ovac increased the electron migration rate and enhanced the photocatalytic performance of $\mathrm{BiVO}_{4}$.

\section{DATA AVAILABILITY STATEMENT}

The original contributions presented in the study are included in the article/supplementary material, further inquiries can be directed to the corresponding authors.

\section{AUTHOR CONTRIBUTIONS}

$\mathrm{XX}, \mathrm{FJ}, \mathrm{YQ}, \mathrm{XG}, \mathrm{QL}$, and YL conceived of the study and designed the experiments. XG, YL, SF, XL, QH, and YZ performed the experiments. XG, YL, QL, and QY analyzed the data. XX, FJ, YQ, and RW contributed reagents, materials, and analysis tools. XG and YL wrote the paper. All authors contributed to the article and approved the submitted version.

\section{FUNDING}

This work was supported by the National Key $R \& D$ Program of China (2018YFD1100501) and the Chongqing Research Program of Basic Research and Frontier Technology (cstc2017jcyjBX0080).

Becke, A. D., and Edgecombe, K. (1990). A simple measure of electron localization in atomic and molecular systems. J. Chem. Phys. 92, 5397-5403. doi: $10.1063 / 1.458517$

Blochl, P. E. (1994). Projector augmented-wave method. Phys. Rev. $B$ Condensed Matter 50, 17953-17979. doi: 10.1103/PhysRevB.50. 17953 
Burdett, J., and McCormick, T. (1998). Electron localization in molecules and solids: the meaning of ELF. J. Phys. Chem. A 102, 6366-6372. doi: $10.1021 /$ jp 9820774

Fujishima, A., and Honda, K. (1972). Electrochemical photolysis of water at a semiconductor electrode. Nature 238, 37-38. doi: 10.1038/238037a0

Grimme, S. (2006). Semiempirical GGA-type density functional constructed with a long-range dispersion correction. J. Comput. Chem. 27, 1787-1799. doi: $10.1002 /$ jcc. 20495

Han, H. S., Shin, S., Kim, D. H., Park, I. J., Kim, J. S., Huang, P.-S., et al. (2018). Boosting the solar water oxidation performance of a $\mathrm{BiVO}_{4}$ photoanode by crystallographic orientation control. Energy Environ. Sci. 11, 1299-1306. doi: $10.1039 / \mathrm{C} 8 \mathrm{EE} 00125 \mathrm{~A}$

Kresse, G., and Furthmüller, J. (1996). Efficiency of ab-initio total energy calculations for metals and semiconductors using a plane-wave basis set. Comput. Mater. Sci. 6, 15-50. doi: 10.1016/0927-0256(96)00008-0

Kudo, A., Omori, K., and Kato, H. (1999). A novel aqueous process for preparation of crystal form-controlled and highly crystalline $\mathrm{BiVO}_{4}$ powder from layered vanadates at room temperature and its photocatalytic and photophysical properties. J. Am. Chem. Soc. 121, 11459-11467. doi: 10.1021/ja992541y

Kudo, A., Ueda, K., Kato, H., and Mikami, I. (1998). Photocatalytic $\mathrm{O}_{2}$ evolution under visible light irradiation on $\mathrm{BiVO}_{4}$ in aqueous $\mathrm{AgNO}_{3}$ solution. Catal. Lett. 53, 229-230. doi: 10.1023/A:1019034728816

Lardhi, S., Cavallo, L., and Harb, M. (2020). Significant impact of exposed facets on the $\mathrm{BiVO}_{4}$ material performance for photocatalytic water splitting reactions. J. Phys. Chem. Lett. 11, 5497-5503. doi: 10.1021/acs.jpclett.0c01234

Li, D., Wang, W., Jiang, D., Zheng, Y., and Li, X. (2015). Surfactantfree hydrothermal fabrication of monoclinic $\mathrm{BiVO}_{4}$ photocatalyst with oxygen vacancies by copper doping. RSC Adv. 5, 14374-14381. doi: $10.1039 / \mathrm{C} 4 \mathrm{RA} 14318 \mathrm{C}$

Liu, S., Li, C., Yu, J., and Xiang, Q. (2011). Improved visible-light photocatalytic activity of porous carbon self-doped $\mathrm{ZnO}$ nanosheet-assembled flowers. CrystEngComm 13, 2533-2541. doi: 10.1039/c0ce00295j

Liu, Y., Zhang, Z., Fang, Y., Liu, B., Huang, J., Miao, F., et al. (2019). IRdriven strong plasmonic-coupling on $\mathrm{Ag}$ nanorices $/ \mathrm{W}_{18} \mathrm{O}_{49}$ nanowires heterostructures for photo/thermal synergistic enhancement of $\mathrm{H}_{2}$ evolution from ammonia borane. Appl. Catal. B Environ. 252, 164-173. doi: 10.1016/j.apcatb.2019.04.035

Lu, N., Sun, M., Wei, X., Zhang, P., and Zhang, Z. (2020). Facile synthesis of lacunary keggin-type phosphotungstates-decorated $\mathrm{g}^{-\mathrm{C}_{3} \mathrm{~N}_{4}}$ nanosheets for enhancing photocatalytic $\mathrm{H}_{2}$ generation. Polymers 12:1961. doi: 10.3390/polym12091961

Monkhorst, H. J., and Pack, J. D. (1976). Special points for brillouin zone integrations. Phys. Rev. B Condensed Matter 13, 5188-5192. doi: 10.1103/PhysRevB.13.5188

Perdew, J., Burke, K., and Ernzerhof, M. (1996). Generalized gradient approximation made simple. Phys. Rev. Lett. 77, 3865-3868. doi: 10.1103/PhysRevLett.77.3865

Qiu, W., Xiao, S., Ke, J., Wang, Z., Tang, S., Zhang, K., et al. (2019). Freeing the polarons to facilitate charge transport in $\mathrm{BiVO}_{4}$ from oxygen vacancies with an oxidative 2D precursor. Angewandte Chemie 58, 19087-19095. doi: 10.1002/anie.201912475

Rao, P. M., Cai, L., Liu, C., Cho, I. S., Lee, C. H., Weisse, J. M., et al. (2014). Simultaneously efficient light absorption and charge separation in $\mathrm{WO}_{3} / \mathrm{BiVO}_{4}$ core/shell nanowire photoanode for photoelectrochemical water oxidation. Nano Lett. 14, 1099-1105. doi: 10.1021/nl500022z

Sayama, K., Nomura, A., Arai, T., Sugita, T., Abe, R., Yanagida, M., et al. (2006). Photoelectrochemical decomposition of water into $\mathrm{H}_{2}$ and $\mathrm{O}_{2}$ on porous $\mathrm{BiVO}_{4}$ thin-film electrodes under visible light and significant effect of $\mathrm{Ag}$ ion treatment. J. Phys. Chem. B 110, 11352-11360. doi: 10.1021/jp057539+

Shi, C., Dong, X., Wang, X., Ma, H., and Zhang X (2018). Ag nanoparticles deposited on oxygen-vacancy-containing $\mathrm{BiVO}_{4}$ for enhanced near-infrared photocatalytic activity. Chin. J. Catal. 39, 128-137. doi: $10.1016 /$ S1872-2067(17)62990-5

Sleight, A. W., Chen, H.-y., Ferretti, A., and Cox, D. E. (1979). Crystal growth and structure of $\mathrm{BiVO}_{4}$. Mater. Res. Bull 14, 1571-1581. doi: 10.1016/0025-5408(72)90227-9

Tokunaga, S., Kato, H., and Kudo, A. (2001). Selective preparation of monoclinic and tetragonal $\mathrm{BiVO}_{4}$ with scheelite structure and their photocatalytic properties. Chem. Mater. 13, 4624-4628. doi: 10.1021/cm0103390
Ullah, H., Tahir, A. A., and Mallick, T. K. (2018). Structural and electronic properties of oxygen defective and Se-doped p-type $\mathrm{BiVO}_{4}(001)$ thin film for the applications of photocatalysis. Appl. Catal. B Environ. 224, 895-903. doi: $10.1016 /$ j.apcatb.2017.11.034

Wadnerkar, N., and English, N. (2013). Density functional theory investigations of bismuth vanadate: effect of hybrid functionals. Comput. Mater. Sci. 74, 33-39. doi: 10.1016/j.commatsci.2013.03.015

Wang, J., Yu, L., Hu, L., Chen, G., Xin, H., and Feng, X. (2018). Ambient ammonia synthesis via palladium-catalyzed electrohydrogenation of dinitrogen at low overpotential. Nat. Commun. 9:1795. doi: 10.1038/s41467-01804213-9

Wang, W., Strohbeen, P., Lee, D., Zhou, C., Kawasaki, J., Choi, K.-S., et al. (2020). The role of surface oxygen vacancies in $\mathrm{BiVO}_{4}$. Chem. Mater. 32, 2899-2909. doi: 10.1021/acs.chemmater.9b05047

Wang, Y., Qiao, M., Li, Y., and Wang, S. (2018). Tuning surface electronic configuration of $\mathrm{NiFe} \mathrm{LDHs}$ nanosheets by introducing cation vacancies (Fe or $\mathrm{Ni}$ ) as highly efficient electrocatalysts for oxygen evolution reaction. Small 14:e1800136. doi: 10.1002/smll.201800136

$\mathrm{Xi}, \mathrm{G}$, and Ye, J. (2010). Synthesis of bismuth vanadate nanoplates with exposed $\{001\}$ facets and enhanced visible-light photocatalytic properties. Chem. Commun. 46, 1893-1895. doi: 10.1039/b923435g

Xu, P., Tang, Q., and Zhou, Z. (2013). Structural and electronic properties of graphene- $\mathrm{ZnO}$ interfaces: dispersion-corrected density functional theory investigations. Nanotechnology 24:305401. doi: 10.1088/0957-4484/24/30/305401

Yang, K., Dai, Y., and Huang, B. (2007). Study of the nitrogen concentration influence on $\mathrm{N}$-doped $\mathrm{TiO}_{2}$ anatase from first-principles calculations. J. Phys. Chem. C 111, 12086-12090. doi: 10.1021/jp067491f

Yuan, Y., Huang, Y., Ma, F., Zhang, Z., and Wei, X. (2017). Effects of oxygen vacancy on the mechanical, electronic and optical properties of monoclinic $\mathrm{BiVO}_{4}$. J. Mater. Sci. 52, 8546-8555. doi: 10.1007/s10853-0171069-7

Zhang, D., Cong, T., Xia, L., and Pan, L. (2019). Growth of black $\mathrm{TiO}_{2}$ nanowire/carbon fiber composites with dendritic structure for efficient visiblelight-driven photocatalytic degradation of methylene blue. J. Mater. Sci. 54, 7576-7588. doi: 10.1007/s10853-019-03424-9

Zhang, Y., Zeng, W., Ye, H., and Li, Y. (2018). Enhanced carbon monoxide sensing properties of $\mathrm{TiO}_{2}$ with exposed (001) facet: a combined first-principle and experimental study. Appl. Surf. Sci 442, 507-516. doi: 10.1016/j.apsusc.2018.02.036

Zhang, Z., Wang, W., Gao, E., Shang, M., and Xu, J. (2011). Enhanced photocatalytic activity of Bi2WO6 with oxygen vacancies by zirconium doping. J. Hazard. Mater 196, 255-262. doi: 10.1016/j.jhazmat.2011. 09.017

Zhao, D., Zong, W., Fan, Z., Fang, Y.-W., Xiong, S., Du, M., et al. (2017). Synthesis of carbon-doped nanosheets $\mathrm{m}-\mathrm{BiVO}_{4}$ with three-dimensional (3D) hierarchical structure by one-step hydrothermal method and evaluation of their high visible-light photocatalytic property. J. Nanoparticle Res. 19:124. doi: 10.1007/s11051-017-3818-6

Zhao, D., Zong, W., Fan, Z., Xiong, S., Du, M., Wu, T., et al. (2016). Synthesis of carbon-doped $\mathrm{BiVO}_{4} @$ multi-walled carbon nanotubes with high visible-light absorption behavior, and evaluation of their photocatalytic properties. CrystEngComm 18, 9007-9015. doi: 10.1039/C6CE0 $1642 \mathrm{~A}$

Zhou, X., and Dong, H. (2017). Density functional studies on layered perovskite oxyhalide $\mathrm{Bi}_{4} \mathrm{MO}_{8} \mathrm{X}$ photocatalysts $(\mathrm{M}=\mathrm{Nb}$ and $\mathrm{Ta}, \mathrm{X}=\mathrm{Cl}, \mathrm{Br}$, and I). J. Phys. Chem. C 121, 20662-20672. doi: 10.1021/acs.jpcc.7b06576

Conflict of Interest: The authors declare that the research was conducted in the absence of any commercial or financial relationships that could be construed as a potential conflict of interest.

Copyright ( $2020 \mathrm{Gu}$, Luo, Li, Wang, Fu, Lv, He, Zhang, Yan, Xu, Ji and Qiu. This is an open-access article distributed under the terms of the Creative Commons Attribution License (CC BY). The use, distribution or reproduction in other forums is permitted, provided the original author(s) and the copyright owner(s) are credited and that the original publication in this journal is cited, in accordance with accepted academic practice. No use, distribution or reproduction is permitted which does not comply with these terms. 